Paideusis

\title{
Editorial Introduction to Special Themed Issue: Working
} Compassion

\section{Heesoon Bai}

Volume 21, Number 2, 2014

Working Compassion

URI: https://id.erudit.org/iderudit/1071560ar

DOI: https://doi.org/10.7202/1071560ar

See table of contents

Publisher(s)

Canadian Philosophy of Education Society

ISSN

0838-4517 (print)

1916-0348 (digital)

Explore this journal

Cite this document

Bai, H. (2014). Editorial Introduction to Special Themed Issue: Working

Compassion. Paideusis, 21(2), 2-4. https://doi.org/10.7202/1071560ar 


\section{Editorial Introduction to Special Themed Issue: Working Compassion}

HEESOON BAI

Simon Fraser University

I am sure that starting an editorial with an apology is not conventional. In her editorial for the last Paideusis Issue, Claudia Eppert announced: "Please stay tuned for our Fall 2013 volume . . guest edited by Heesoon Bai." Thank you all for staying tuned overtime patiently! My apologies for breaking my promise to edit and publish the Working Compassion volume in 2013. I did not end up in the hospital or anything like that. Increasingly, though, I have been operating under the spell of what I have come to call the Tyranny of Urgencies. In any given day, there are always some urgent businesses to attend to: someone or something that demands my top priority attention. Demands on my plate get shuffled and reordered to reflect the degree of urgency I experience. Tasks that didn't become, to exaggerate a bit, "life-and-death" issues fall to the bottom of my priority list.

This priority business has been worrying me greatly. Have ethical concerns made into people's priority list? Is compassion on our priority list?

The other day, I was watching Daniel Goleman's TED TALK called, Why aren't we more compassionate? Daniel Goleman is the author of Emotional Intelligence, a book that's now in print in 40 languages. In his TED talk, he tells the story of an experiment that was undertaken with a group of divinity students at Princeton Theological Seminary. These students were told that they had to give a sermon in another building. Half of the students were given the sermon topic of the parable of the Good Samaritan; the other half, on some random topics. As these students were making their way to the building where they needed to give a sermon, they had to pass by a bent-over groaning figure on the ground who was clearly in pain. Did these students stop to help? Did those who stopped to help study the parable of the Good Samaritan?

In fact, it turned out there was no relationship whatsoever between those who were studying the parable of the Good Samaritan and those who stopped to help the stranger in need. The determinant was simply whether the students were in a hurry or not. Those who thought they were in a great hurry just walked past the suffering person. Probably some of them did not even notice the person.

Goleman reminds us that we are, as it were, evolutionarily preprogrammed to respond to others' distress and help. Such response is automatic. We don't have to stop to think about it. Indeed, contemporary infant morality studies as well as studies on primates' moral behaviour all reveal the 'preprogrammed' nature of our moral response at the foundational level. Compassion is our most natural, therefore spontaneous, response to the perceived situations of others in distress. Given all this, the puzzling question is: why aren't there more manifestations of compassion in/for/toward the world? There is all too much suffering in the human and the 'more-than-human' world!

Goleman proposes a compelling answer to the above question. Yes, we are naturally disposed to be compassionate and helpful, but we encounter factors in real life that prevent us from more fully manifesting our compassion. One of these factors, perhaps the main factor, is being in a hurry. This is really bad news for fast-paced cultures like ours!

(C) Copyright 2014. The author, Heesoon Bai, assigns to Paideusis the right of first publication and educational and non-profit institutions a non-exclusive license to use this document for personal use and in courses of instruction provided that the article is used in full and this copyright statement is reproduced. Any other usage is probibited without the express permission of the author. 
As an educator and researcher in moral philosophy, I am interested in the question of conditions of compassion. What are the conditions under which compassion could show up? What are the challenges that restrict and compromise the manifestations of compassion? These are no idle curiosity questions. Rather, understanding the affordance conditions of compassion would be vitally important for educators and anyone who are in the helping professions, as well as, really, all concerned and caring ordinary people.

The seed for this special issue was planted two years ago. Simon Fraser University (SFU) conferred the prestigious Jack P. Blaney Award for Dialogue to Karen Armstrong on March 20, 2012. This award is presented to "an individual who has demonstrated, internationally, excellence in the use of dialogue to further the understanding of complex and profound public issues" (Centre for Dialogue, About the Blaney Award, para. 1). Karen Armstrong launched the Charter for Compassion in 2009 with the $\$ 100,000$ TED Prize she won in 2008. Since the unveiling of this charter, Karen Armstrong has been tirelessly spreading the compassion network all over the world.

As part of Karen Armstrong's visit to Vancouver to receive the Blaney Award, the Simon Fraser Centre for Dialogue, in conjunction with Simon Fraser University's Faculty of Education, and generously supported by CSSE (Canadian Society for the Study of Education) and SFU's Centre for Education, Law \& Society, my colleagues and I programmed one full-day Symposium with Karen Armstrong on the title of Working Compassion. Over 100 invited attendees gathered to inquire into the complex, complicated, and challenging phenomena of compassion and to share our experience of compassion-suffering and joy, heartaches and concerns - in all the places that our invited guests walked and worked. It was an emotionally, morally, and intellectually heartening and stimulating day. At the conference, I promised everyone that I would put together a Special Issue on the same topic. This volume is a witness to the growth of that small seed.

Why the title, Working Compassion? With this title, I want to signal that compassion is a demanding work that involves all our faculties and facilities comprising mind-body-heart-spirit (and whatever else is part of this ontological package called human being). We have the capacity for being compassionate, but capacity is not ability: it takes disciplined, and often hard, work to cultivate and manifest compassion. All the articles that this volume has collected speak to this single point, in so many different ways with different inflections. We are evolutionarily primed to be compassionate, but also by the same endowment, we are designed to want to protect or remove ourselves from suffering. Facing the prospect of suffering, our survival mandate and neural circuitry kicks in, and if we can, we want to move away from the source of affliction. So we can see there is an inherent tension engineered into our being between moving both away from and also towards suffering. When we cannot successfully hold this tension, we fall off to either side of the tightrope. This is where the abovementioned demanding work of compassion comes in.

Our ability to be compassionate is activated by the face of suffering. But if we avoid, intentionally or unintentionally, the sight of suffering, because we cannot tolerate it - too painful, traumatic, scary, threatening - then we have successfully avoided the activation. Thus, the very first step in our compassion work is to increase our capacity to sit with and in suffering, with our heart fully open. This can be extremely hard and challenging work. David Jardine and his coauthor colleagues, Graham McCaffrey and Christopher Gilham, have written a compelling article on the pedagogy of suffering. In their lucid composition of Four Fragments, they attempt to "understand and articulate how and why suffering can be pedagogical in character and how it is often key to authentic and meaningful acts of teaching and learning". Suffering in all shades and varieties abound in everyday life, and therefore any attempt to live well must embrace suffering and work with it. Only then can we transform it into compassion and wisdom.

In a similar vein, Susan Walsh explores in her reflective narrative piece the dynamics around heart wounding and its relationship to experiencing difficulty in being generously compassionate. The ego's way to protect its wounded heart-all those million ways that we feel wronged, invalidated, unmet, ignored, neglected-is to clamp up and shut down the heart to protect itself from further bleeding and getting further wounded. Opening the heart is a difficult practice that requires much courage, commitment, and, perhaps ironically, compassion for the self. Please join Susan in her wonderful effort.

Although compassion is such challenging work, we are not without resources. While no one tradition of wisdom has a monopoly on compassion work, today many scholars are discovering the wonderful and powerful resources in the Buddhist contemplative and psychological tradition. Mei Hoyt, along with many 
contributors to this volume, has drawn resources from the Buddhist tradition with its explicit and welldeveloped 'program' of bodhisattva ways of being. As she puts it, "bodhisattva compassion focuses on lucid awareness of one's responsive heartmind and skillful actions to engage suffering" (from Abstract). Her own classrooms, in handling identity politics and social justice issues, are a ripe field of bodhisattva compassion work, where students and educators alike experience the constant tension and discomfort arising from power dynamics and struggles, conflict and ruptures.

Another wisdom tradition that is featured in this volume for providing a powerful resource and support for compassion work is Daoism. Tom Culham explores the Daoist cosmogony to reveal that the Daoist philosophical basis of compassion is the dao. This dao is a 'more-than-human' power inherent in all beings, including all human beings, regardless of their moral manifestations. The 'impersonal' nature of dao calls for compassion that is not defined by individual likings and dislikings, and calculations of desert. All beings qua ontological manifests deserve our compassion, and its supports - frugality and humility. These three comprise the "Three Treasures" in Daoism. By freeing compassion from the calculative thinking of who deserves it and how much, compassion becomes a true force of nature, and can thus serve the world in the widest possible ways. Please join Culham in his exploration of how to cultivate such a profound virtue, and how to bring it into one's classroom learning and teaching.

Daoism, Buddhism, and care ethics all share the foundation of human development: the need for unconditional love, nurturance, and care, as experienced in secure child-parent bonding. Compassion, along with its affinity virtues of good will and empathic joy, are essential for human survival, growth and flourishing. Deborah Orr has positioned herself on this moral foundation to explore the complexity and richness of philosophical concepts of selfhood and entailed ethical theorizing through her rich scholarship in East-West comparative philosophy. She brings together Nargarjuna of the East and Wittgenstein of the West, both of whom had deep insight into our languaged mind, to bear upon the mutually supportive tasks of (a) dispelling the illusion of what we may call the atomistic sense of self (or the ego-self) that limits our compassion, (b) extending and deepening the natural care of the paradigmatic parent-child relationship, and (c) introducing the practice of mindfulness to promote compassion. You are invited to explore the complexity and richness involved in Orr's East-West scholarship on the topic.

The last but not least piece to be featured in this Special Issue takes us out into the community. Susan Walsh and her coauthor colleagues, Fabiana Gonzalez, Philip Joy, and Kim MaCaulay have written an article about a non-profit community-based organization called Waves of Compassion in Nova Scotia, Canada. The article explores how this young organization grapples with the "hard questions" about sociocultural marginality, inequity, discrimination, and inclusivity as it engages in creating an inclusive public culture of compassion. Through found poems and expository writings, Walsh and her colleagues explore ways to listen, deeply, into and beyond all categories of dualistic separations that constitute our ordinary consciousness. Such categories tend to block the generous movement of compassion. Please join Walsh and her colleagues in this deep listening.

May this Special Issue be a deep listening space for us all as we contemplate the challenges and possibilities of compassion work in our personal and professional worlds!

In concluding this editorial, I offer gratitude and appreciation: Thank you, Jim Bigari, Paideusis copyeditor, for all your steadfast and skillful help and support. Also a hearty Thank-you with a bow to all the reviewers who responded so promptly to my request for submission reviews and rendered their deft expert help with constructive revision suggestions. I thank the Editorial Team members for their infinite patience with me: in particular, Editors-in-Chief, Claudia Eppert and Daniel Vokey for their unfailing support for me with this Special Issue, and over the long collegial years we have known each other. I also would like to take this occasion to express my delighted welcome greetings to our new President of Canadian Philosophy of Education Society (CPES), Douglas Simpson, along with notes of appreciation for Ann Chinnery, SecretaryTreasurer, for her diligent and devoted work for CPES, and for Michelle Forrest, Past-President of CPES. 